\title{
Fishing power increases continue in Queensland's east coast trawl fishery, Australia
}

\author{
Michael F. O’Neill*, George M. Leigh ${ }^{1}$ \\ Southern Fisheries Centre, Department of Primary Industries and Fisheries, P.O. Box 76, Deception Bay, Qld 4508, Australia
}

Received 21 July 2006; received in revised form 6 December 2006; accepted 18 December 2006

\begin{abstract}
The Queensland east coast trawl fishery is by far the largest prawn and scallop otter trawl fleet in Australia in terms of number of vessels, with 504 vessels licensed to fish for species including tiger prawns, endeavour prawns, red spot king prawns, eastern king prawns and saucer scallops by the end of 2004. The vessel fleet has gradually upgraded characteristics such as engine power and use of propeller nozzles, quad nets, global positioning systems (GPS) and computer mapping software. These changes, together with the ever-changing profile of the fleet, were analysed by linear mixed models to quantify annual efficiency increases of an average vessel at catching prawns or scallops. The analyses included vessel characteristics (treated as fixed effects) and vessel identifier codes (treated as random effects). For the period from 1989 to 2004 the models estimated overall fishing power increases of $6 \%$ in the northern tiger, $6 \%$ in the northern endeavour, $12 \%$ in the southern tiger, $18 \%$ in the red spot king, $46 \%$ in the eastern king prawn and $15 \%$ in the saucer scallop sector. The results illustrate the importance of ongoing monitoring of vessel and fleet characteristics and the need to use this information to standardise catch rate indices used in stock assessment and management.

Crown Copyright (C) 2007 Published by Elsevier B.V. All rights reserved.
\end{abstract}

Keywords: Fishing power; Linear mixed models; Prawns; Scallops; Otter trawling

\section{Introduction}

Harvest landings from the Queensland east coast otter trawl fishery (ECOTF) are in the order of 10-13 kilo-tonnes annually and worth approximately \$100-150 million (AUD) at the wharf. With 504 vessels licensed at the end of 2004, the ECOTF is by far the largest prawn trawl fleet in Australia in terms of the number of vessels. The fishery is complex in nature targeting several species of prawns (mainly Penaeus spp., Melicertus spp. and Metapenaeus spp.) and one main species of scallop (Amusium balloti). The ECOTF is characterised by identifiable sectors that are largely based on target species and geographic regions (Fig. 1).

Vessel characteristics change through the adoption of new and better technologies and fishing gear, and individual license holders are free to target any sector they choose. Consequently, interpretation of the catch and effort statistics, and the use

\footnotetext{
* Corresponding author. Tel.: +61 73817 9560; fax: +61 738179555.

E-mail address: michael.o'neill@dpi.qld.gov.au (M.F. O’Neill).

1 Present address: Julius Kruttschnitt Mineral Research Centre, The University of Queensland, Isles Road, Indooroopilly, Qld 4068, Australia.
}

of these statistics for monitoring the status of the fishery and reviewing the suitability of management arrangements are more difficult.

Catch and effort statistics are used as the basis of stock assessments and management in many Australian fisheries (O'Neill and Leigh, 2006). Predictions based on raw data can be biased due to changes in the efficiency of fishing effort through time and between fishing operations or sectors. There is, therefore, a need to standardise catch and effort data to reduce biases and variability. Standardisation, accounting for factors affecting both relative abundance and fishing efficiency, results in time series of catch and effort data that are more representative of trends in population abundance.

Several studies have focussed on standardisation of catcheffort data (Bishop et al., 2000, 2004; Hall and Penn, 1979; O'Neill et al., 2003; Robins et al., 1998; Salthaug and Godø, 2001). Generalised linear regression models (GLM) have been used to estimate changes in relative fishing power and to standardise average catches in the Queensland trawl fishery (O'Neill et al., 2003). They have also been used to quantify the effects of global positioning system (GPS) on average catches in Australia's northern prawn fishery (Robins et al., 1998). Bishop et al. (2000) further developed the analysis of Robins et al. (1998) 


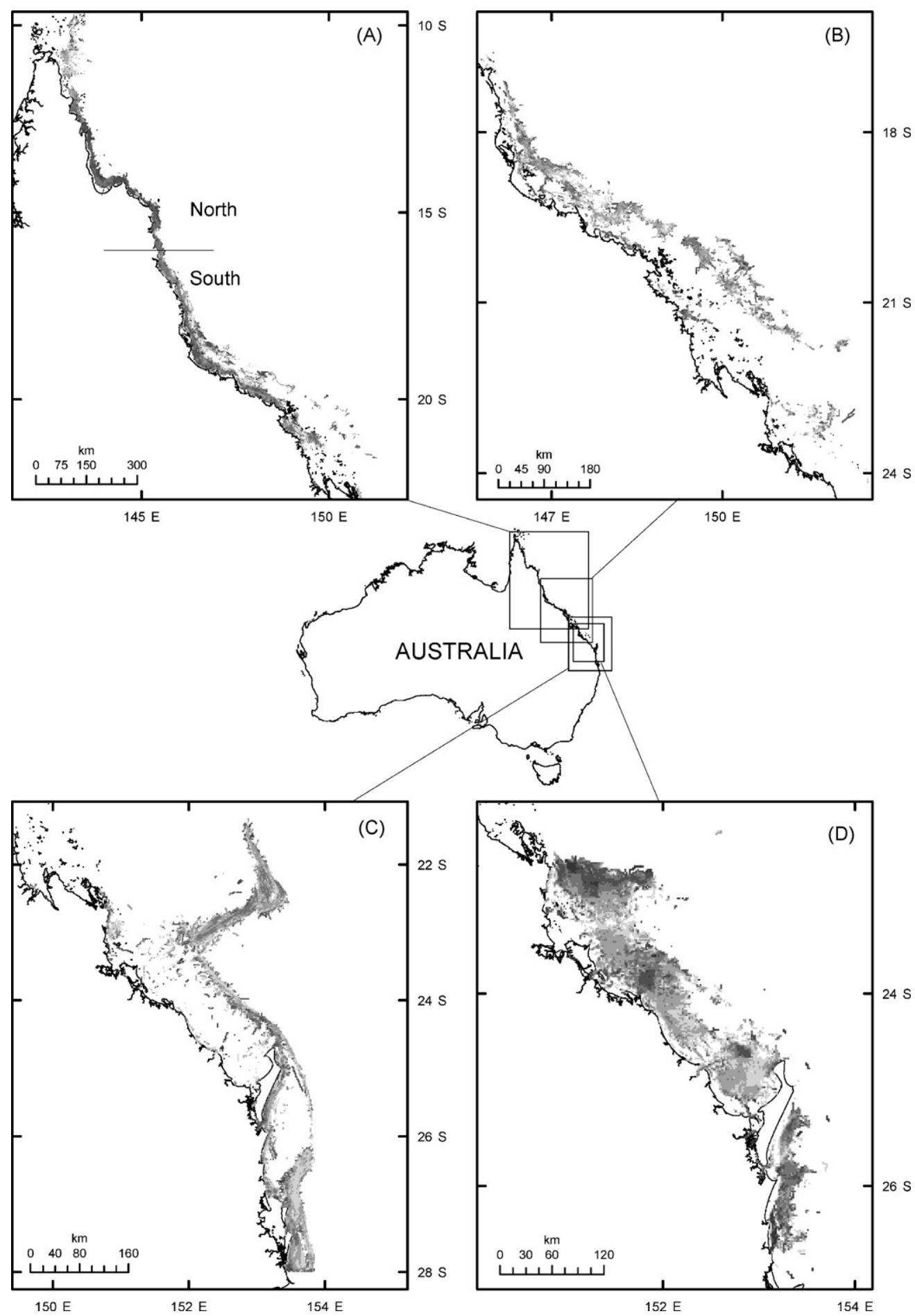

Fig. 1. Spatial distribution of normalised (log transformed) catch rates for: (A) tiger and endeavour prawn, (B) red spot king prawn, (C) eastern king prawn and (D) saucer scallop; the darker shades indicate high catching areas. The horizontal line in (A) at $16^{\circ} \mathrm{S}$ distinguishes the northern and southern tiger/endeavour prawn trawl sectors.

by using generalised estimating equations (GEE) to account for spatial and temporal correlations in the data. A linear mixed model (LMM) for catches from Australia's northern prawn fishery 'produced consistent results when compared with ... other random vessel models' (Bishop et al., 2004).

In recent years, the Queensland and Australian governments have addressed Queensland's trawl fishing power increases by reducing the total number of nights that vessels are allowed to fish, through the use of penalties for vessel upgrades and surrender provisions on licence and effort trading (Kerrigan et al., 2004). 'Fishing power' is the term used to describe the efficiency of an average vessel at catching prawns or scallops. The concept of reducing fishing time (measured in nights) according to potential fishing power increases was implemented by fishery 
managers to ensure that effective effort was capped in both the fishery and the Great Barrier Reef Marine Park (O'Neill and Leigh, 2006).

In this paper, linear mixed models are used to quantify fishing power increases from 1988 to 2004. Since previous estimates up to 1999 were published (O'Neill et al., 2003), a further comprehensive survey of fishing operators has been conducted and several more years of catch and effort data have been gathered. Our methods and results further the application of linear mixed models in fisheries research and the calculation of annual fishing powers for use in management.

\section{Methods}

\subsection{Catch data}

Analyses were based on compulsory daily logbook data reported by individual vessels from 1988 to 2004 for their catches of tiger prawn (Penaeus esculentus), endeavour prawn (Metapenaeus endeavouri), red spot king prawn (Melicertus longistylus), eastern king prawn (Melicertus plebejus) and saucer scallop (Amusium balloti). The spatial resolution of catches recorded was $30 \times 30$ min grids. All data were analysed by vessel codes that identified the combination of vessel hull and owner. Our analysis relates only to prawns recruited to offshore fisheries (i.e. greater than about $20 \mathrm{~mm}$ carapace length); this is consistent with stock assessments (O’Neill et al., 2005).

The fishing year for eastern king prawns and saucer scallops was defined to start in November and end in October, to match the cycle of fishing and recruitment to these fisheries (O'Neill et al., 2005). The fishing year for tiger, endeavour and red spot king prawns was defined as a calendar year; this definition suited the life-cycle and seasonal variation in fishing effort for these species (O'Neill and Leigh, 2006). Estimates for the 2004 fishing year were based only on the months up to April; we consider the results indicative for that year as the data covered the peak fishing months. O'Neill and Leigh (2006) describe the data in more detail.

\subsection{Vessel and fishing gear data}

The analyses considered many different vessel characteristics thought to affect fishing power. Information on when particular fishers adopted new devices and technologies was obtained from two purposely-designed surveys of past and present Queensland ECOTF vessel owner/operators in 2000 and 2004. These data represented, from each trawl sector, a random set of vessels that had fished between 1997 and 2004. The surveys had participation rates of 85 and $84 \%$, respectively, of the operators contacted and collectively covered about $60 \%$ of each sector's harvest in the later years (2002-2004). Further details on the survey questionnaire, coverage and sample sizes are given by O'Neill and Leigh (2006) and O'Neill et al. (2003, 2005).

Interviewees provided records of vessel characteristics during personal (face-to-face) interviews. Changes in the following characteristics, and the date of each change, were recorded for each vessel; for the benefit of interviewees, the surveys used a mix of metric and imperial measurement units, according to prevailing industry usage:

- Engine power (HP), gear box ratio (reduction), average trawl speed (knots), fuel capacity (litres), fuel consumption per night (litres), propeller size (inches) and presence or absence of a propeller nozzle.

- Navigation equipment: presence or absence of global positioning system and plotters, computer mapping software, sonar and colour sounder.

- The use, position, type and size of try-gear; try-gear is a small (1-3 fathom) net used for frequent 10-20 min sampling of trawl grounds.

- The type and use of by-catch reduction devices (BRD) and turtle exclusion devices (TED).

- Trawl net configurations: number of nets (single, double, triple, quad or five nets), total net head rope length (fathoms) combined for all nets, net mesh size $(\mathrm{mm})$, type of ground chain (fixed drop chain, drop chain with sliding rings, drop rope and chain combined, looped chain or other less common configurations), chain size (mm), type of otter board (Bison, flat, Kilfoil, Louvre or other less common types) and size (total board area $=$ board length $\times$ width).

\subsection{Statistical analyses}

Linear mixed models were applied using the method of residual maximum likelihood (REML) assuming normally distributed errors on the log scale (GenStat, 2005; Montgomery, 1997). The response variable was the individual vessel daily catch by species for a spatial area, measured in kilograms of prawns or baskets of saucer scallops. The models included as explanatory variables the fishing year, month, spatial logbook $30 \times 30$ min grid square, lunar cycle, corresponding catches of other prawn or scallop species and the vessel's gear characteristics. Lunar variation in catches was modelled by a calculated luminance measure ranging between 0 for new moon and 1 for full moon (Courtney et al., 2002). This luminance measure followed a sinusoidal pattern, and was also replicated and advanced 7 days ( $\sim(1 / 4)$ lunar period) to provide an additional degree of freedom for a potential time lag in the response of fisheries to lunar luminance. Together these patterns model a cyclic variation in catches corresponding to new moon, waxing moon, full moon and waning moon phases, and allow the peak catch to occur in any one of these phases. The associated catches of other prawns or scallops were included to adjust for catchability effects when they were caught with the main target prawn or scallop species.

The linear mixed model included both fixed and random model terms. Fixed terms were used for all of the explanatory variables described above. Random terms treat an attribute as a random selection from an overall population. Random terms covered individual vessels in the trawl fleet. Mixed models measure multiple sources of variation in the data, thus providing estimates of variance components associated with random terms in the model. Mixed models have the advantage that the significance of the fixed terms can be assessed considering more than one source of error, improving the accuracy of significance tests. 
The model was also able to measure changes in fleet profile not covered by fixed effects, as vessels switched sectors or exited the fishery; these were not modelled by O'Neill et al. (2003).

Definition of the model was as follows:

$\log _{e} \mathbf{C}=\mathbf{X} \boldsymbol{\alpha}+\mathbf{Z} \boldsymbol{\gamma}+\boldsymbol{\varepsilon}$

where $\mathbf{C}$ is the vector of catches; $\boldsymbol{\alpha}$ a vector of fixed terms including $\beta_{0}, \boldsymbol{\beta}_{1}, \boldsymbol{\beta}_{2}, \boldsymbol{\beta}_{3}$ and $\boldsymbol{\beta}_{4}$, matrix-multiplied by data $\mathbf{X}$ (composed of $\mathbf{X}_{1}, \mathbf{X}_{2}, \mathbf{X}_{3}$ and $\mathbf{X}_{4}$ ); $\boldsymbol{\gamma}$ a vector of random vessel terms with design matrix $\mathbf{Z}$ indicating which daily catches belong to each vessel and $\boldsymbol{\varepsilon}$ is a normally distributed error term. Parameter $\beta_{0}$ is a scalar intercept, while $\boldsymbol{\beta}_{1}, \boldsymbol{\beta}_{2}, \boldsymbol{\beta}_{3}$ and $\boldsymbol{\beta}_{4}$ are vector parameters for abundance, catchability, lunar phase and logarithms of corresponding catches of other species, respectively. The abundance vector $\boldsymbol{\beta}_{1}$ consisted of categorical terms for fishing grids, fishing years and months, and their two-way interactions. The catchability vector $\boldsymbol{\beta}_{2}$ included vessel characteristics, navigation equipment, by-catch reduction devices and trawl net configurations, of which some were categorical and others continuous; a log scale was used for the continuous terms. The vector $\boldsymbol{\beta}_{3}$ consisted of a term for lunar luminance and one for luminance advanced seven days. The fishing power components $\boldsymbol{\beta}_{2}$ and $\boldsymbol{\gamma}$ were the exclusive focus of interpretation to calculate annual changes in fishing power.

The statistical software package GenStat (2005) was used for the analysis and provided asymptotic standard errors for all estimates. Any influential correlations of parameter estimators were assessed and removed if necessary. The importance of individual terms in the linear mixed model was assessed formally using Wald statistics. Wald statistics were calculated by dropping individual fixed terms from the full model. They have asymptotic chi-squared distributions with degrees of freedom equal to those of the fixed model terms (GenStat, 2005). Analysis of residuals from each model, and the importance of having multiplicative errors, supported the use of the normal residual distribution on the log scale (O'Neill and Leigh, 2006).

For the eastern king prawn sector, annual changes in fishing power were calculated for two management sectors: water depths $\leq 50$ fathoms (shallow) and waters $>50$ fathoms (deep). Net sizes were modelled by their log-residuals to adjust for management bias allowing larger nets in deep waters (O'Neill and Leigh, 2006). The log-residuals were calculated from the simple regression of net size (log transformed) against depth category (shallow or deep). This was to ensure that catch variations with net size were quantified according to vessel differences and were not due to management limitations on net sizes in the different waters. Spatial weightings of $45 \%$ for shallow waters and $55 \%$ for deep waters were applied to correct for the imbalance of shallow $(29 \%)$ versus deep water $(71 \%)$ grid squares in which it was certain whether shallow or deep water fishing nets were used; many predominantly shallow-water squares also contained some deep water and therefore could not be classified with certainty.

\subsection{Estimating relative fishing power}

Relative fishing power was calculated as a proportional change in average catch rates from fishing year to fishing year under standard conditions. The expected catch on each day fished by each vessel was calculated as

$\mathbf{c}=\exp (\mathbf{X} \boldsymbol{\alpha}+\mathbf{Z} \boldsymbol{\gamma})$

where $\mathbf{c}$ is the vector of expected catches under standard conditions for each vessel and day fished and $\mathbf{X}, \boldsymbol{\alpha}, \mathbf{Z}$ and $\boldsymbol{\gamma}$ are as in Eq. (1). Within $\mathbf{X} \boldsymbol{\alpha}$, the terms represented by $\beta_{0}, \mathbf{X}_{1} \boldsymbol{\beta}_{1}, \mathbf{X}_{3} \boldsymbol{\beta}_{3}$ and $\mathbf{X}_{4} \boldsymbol{\beta}_{4}$ were held constant to provide standard conditions of abundance, lunar phase and catches of other species, thus enabling prediction of changes in fishing power. Annual fishing power increases due to trawling more on favourable lunar phases were not considered, because changes in the lunar pattern of fishing in each trawl sector were negligible over the period 1988-2004 (O’Neill and Leigh, 2006).

An average catch $\bar{c}$ was defined for each fishing year as the arithmetic mean of elements of $\mathbf{c}$ that were within the year. The fishing power was then defined as

$\mathbf{f}_{\mathrm{y}}=\frac{\overline{\mathbf{c}}}{\overline{\boldsymbol{c}}_{1989}}$

where $\mathbf{f}_{\mathrm{y}}$ is the vector of proportional change in average catch relative to 1989 and $\overline{\mathbf{c}}$ is the vector of annual average catches under standard conditions. The reference fishing year was chosen as 1989 because it was the first fishing year with complete catch records across all sectors, and for consistency with previous work (O’Neill et al., 2003).

Confidence intervals on fishing power estimates from each trawl sector were generated by a Monte Carlo routine of running the model predictions for 1000 realisations of the parameter estimates. The variations in fixed parameters were calculated using the parameter estimates and their covariance matrix to construct a multivariate normal distribution of values. Realisations of the random vessel effects were calculated from normal distributions based on the means and standard deviations for vessels fishing in each fishing year, month and grid square. Calculated 2.5 and $97.5 \%$ percentiles on the fishing power distributions represented $95 \%$ confidence intervals. As the reference fishing-power year was 1989, the confidence intervals increase in size away from this fishing year. For more information on the Monte Carlo routine see O'Neill et al. (2005).

\section{Results}

\subsection{Analyses and parameter estimates}

Table 1 lists the model statistics and parameter estimates for the various gears and technologies for tiger prawns, endeavour prawns, red spot king prawns, eastern king prawns and saucer scallops. The statistics show that the fishing power $\boldsymbol{\beta}_{2}$ parameters (including different vessel characteristics, navigation equipment, by-catch reduction devices and trawl net configurations) were highly significant $\left({ }^{* * *} P<0.001\right)$ after accounting for abundance $\boldsymbol{\beta}_{1}$ (parameterised as location, fishing year, month and their two-way interactions), lunar phase $\boldsymbol{\beta}_{3}$ and catches of other species $\boldsymbol{\beta}_{4}$. Variance components for the random vessel terms in the different sectors ranged between 0.0509 (equivalent to a coefficient of variation (c.v.) of 
Table 1

Summary of analyses, parameter estimates $\boldsymbol{\beta}_{2}$ and standard errors in parentheses from the mixed linear models for each trawl sector

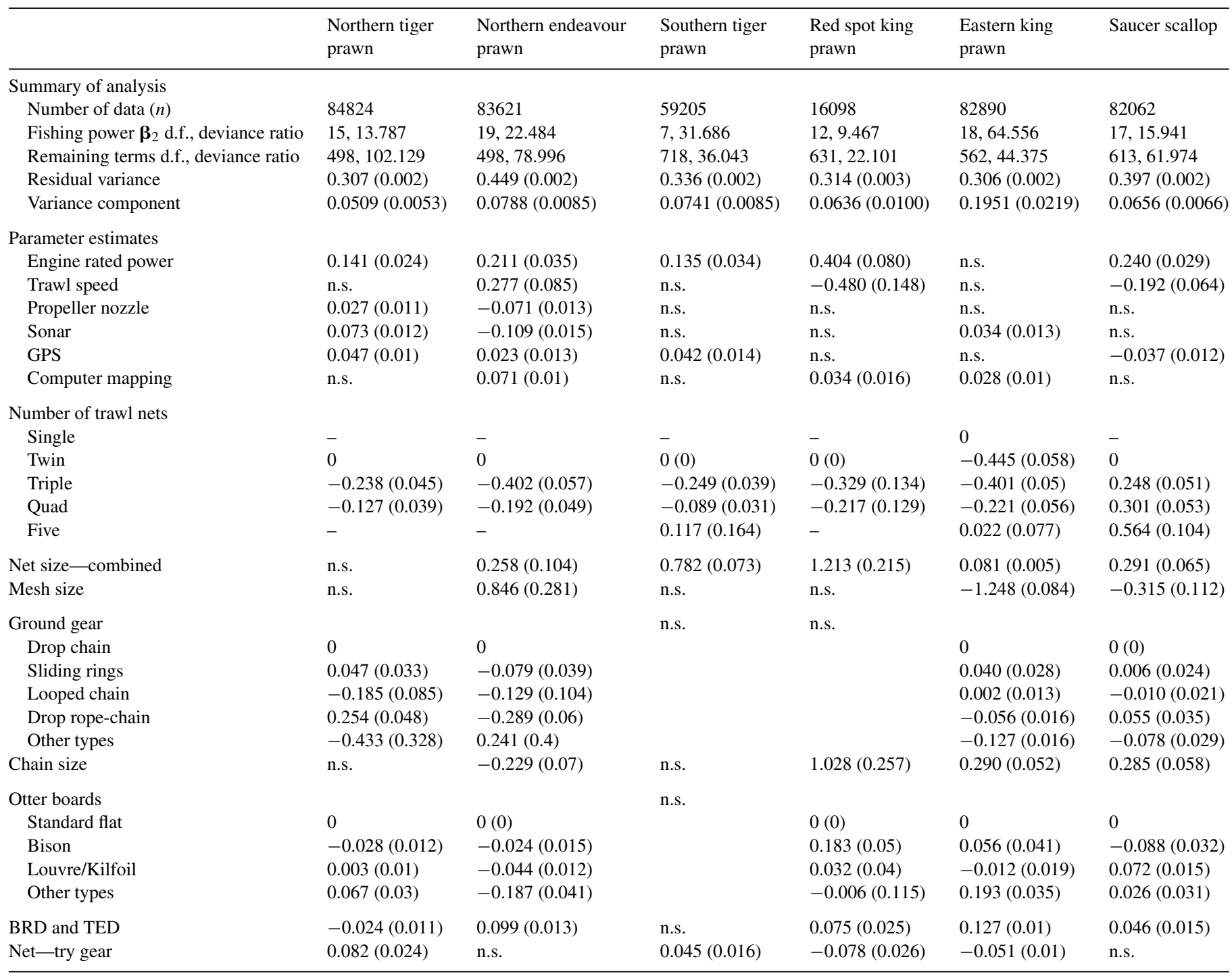

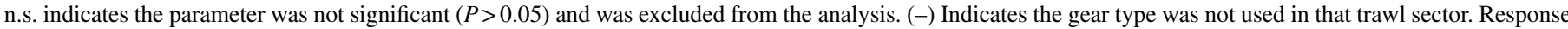
variable and continuous explanatory variables were natural log transformed.

$0.0509^{1 / 2}=22.6 \%$ ) and 0.1951 (c.v. $44.2 \%$ ), thereby accounting for a large part of the variation in vessels' annual catches.

Fishing power estimates are listed in Table 2 and show, for the period from 1989 to 2004 , increases of $6 \%$ in the northern tiger, $6 \%$ in the northern endeavour, $12 \%$ in the southern tiger, $18 \%$ in the red spot king, $46 \%$ in the eastern king prawn and $15 \%$ in the saucer scallop sector. These results are described in detail in Section 3.2 below.

Higher engine power was associated with higher catches in all trawl sectors except eastern king prawn (Table 1). Examination of predicted values from the model indicated that vessels with $50 \mathrm{HP}$ extra engine power generally achieved 2-8\% larger average catches. The random vessel term (variance component) was largest for the eastern king prawn sector. Slower trawl speeds by (1/2) knot were associated with between 3 and 7\% larger average catches of saucer scallops and red spot king prawns, respectively. Vessels installed with sonar were associated with having 7 and $3 \%$ better average catches of northern tiger and east- ern king prawns, respectively. The effect of global positioning systems differed between trawl sectors. For tiger and endeavour prawns, vessels with GPS achieved 2-5\% larger average catches, respectively. However, larger catches of red spot king prawns, eastern king prawns and saucer scallops were not correlated with GPS. Vessels fishing for endeavour, red spot king and eastern king prawns with computer mapping software, such as Cplot, made on average 3-7\% larger catches. Vessels using quad nets achieved 5-23\% better average prawn catches than vessels using triple gear. Generally, larger catches were associated with larger net sizes and (for eastern king prawns and saucer scallops at least) smaller mesh sizes. Drop-chain ground gear was generally used most and was associated with better than average catches. Larger ground chains, typically made from $12 \mathrm{~mm}$ versus the smaller $10 \mathrm{~mm}$ diameter steel, were associated with $5 \%$ better average catches of eastern king prawns and saucer scallops, and $20 \%$ better catches of red spot king prawns. Bison and Louvre otter-boards were generally associated with better 
Table 2

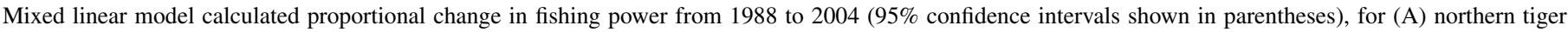

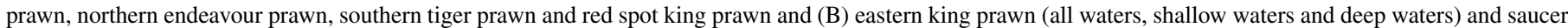
scallop

\begin{tabular}{|c|c|c|c|c|}
\hline \multicolumn{5}{|l|}{ (A) } \\
\hline Fishing year & Northern tiger prawn & Northern endeavour prawn & Southern tiger prawn & Red spot king prawn \\
\hline 1988 & $0.956(0.944,0.961)$ & $0.971(0.954,0.981)$ & $0.928(0.911,0.937)$ & $1.095(1.044,1.161)$ \\
\hline 1989 & 1 & 1 & 1 & 1 \\
\hline 1990 & $0.949(0.938,0.958)$ & $0.950(0.929,0.960)$ & $1.074(1.063,1.098)$ & $1.097(1.026,1.175)$ \\
\hline 1991 & $0.967(0.954,0.979)$ & $0.983(0.961,0.997)$ & $0.996(0.984,1.013)$ & $1.045(0.975,1.108)$ \\
\hline 1992 & $0.963(0.950,0.977)$ & $0.988(0.971,1.005)$ & $1.012(0.995,1.034)$ & $1.029(0.964,1.075)$ \\
\hline 1993 & $0.982(0.967,0.992)$ & $0.992(0.970,1.007)$ & $1.039(1.023,1.062)$ & $1.144(1.081,1.196)$ \\
\hline 1994 & $0.967(0.950,0.979)$ & $0.987(0.964,1.005)$ & $1.054(1.043,1.084)$ & $1.108(1.055,1.157)$ \\
\hline 1995 & $0.984(0.967,1.000)$ & $1.013(0.980,1.029)$ & $1.088(1.079,1.124)$ & $1.047(0.992,1.093)$ \\
\hline 1996 & $0.975(0.959,0.994)$ & $0.942(0.912,0.956)$ & $1.101(1.091,1.144)$ & $1.029(0.978,1.071)$ \\
\hline 1997 & $1.013(0.992,1.032)$ & $1.014(0.982,1.033)$ & $1.068(1.050,1.095)$ & $1.045(0.997,1.091)$ \\
\hline 1998 & $0.997(0.978,1.015)$ & $1.022(0.993,1.045)$ & $1.046(1.027,1.072)$ & $1.107(1.050,1.162)$ \\
\hline 1999 & $1.018(0.996,1.040)$ & $1.065(1.030,1.096)$ & $1.143(1.121,1.174)$ & $1.074(1.012,1.124)$ \\
\hline 2000 & $1.041(1.011,1.070)$ & $1.112(1.061,1.146)$ & $1.098(1.071,1.125)$ & $1.162(1.085,1.228)$ \\
\hline 2001 & $1.046(1.018,1.075)$ & $1.094(1.052,1.135)$ & $1.035(1.013,1.061)$ & $1.089(1.012,1.155)$ \\
\hline 2002 & $1.059(1.030,1.088)$ & $1.125(1.081,1.173)$ & $1.089(1.062,1.118)$ & $1.137(1.059,1.215)$ \\
\hline 2003 & $1.079(1.049,1.111)$ & $1.132(1.088,1.182)$ & $1.078(1.052,1.107)$ & $1.168(1.079,1.256)$ \\
\hline 2004 & $1.060(1.027,1.093)$ & $1.064(1.023,1.123)$ & $1.118(1.086,1.158)$ & $1.177(1.073,1.268)$ \\
\hline \multicolumn{5}{|l|}{ (B) } \\
\hline & $\begin{array}{l}\text { Eastern king prawn: } \\
\text { depths combined }\end{array}$ & $\begin{array}{l}\text { Eastern king prawn: } \\
\text { depths } \leq 50 \text { fathoms }\end{array}$ & $\begin{array}{l}\text { Eastern king prawn: } \\
\text { depths }>50 \text { fathoms }\end{array}$ & Saucer scallop \\
\hline 1988 & $1.028(1.017,1.053)$ & $0.965(0.948,1.006)$ & $1.012(0.994,1.028)$ & $0.975(0.958,0.994)$ \\
\hline 1989 & 1 & 1 & 1 & 1 \\
\hline 1990 & $1.053(1.036,1.073)$ & $1.073(1.047,1.107)$ & $1.018(1.003,1.032)$ & $1.025(1.012,1.038)$ \\
\hline 1991 & $1.062(1.054,1.087)$ & $1.111(1.096,1.152)$ & $0.983(0.970,0.998)$ & $1.036(1.018,1.051)$ \\
\hline 1992 & $1.064(1.053,1.086)$ & $1.121(1.100,1.156)$ & $0.978(0.966,0.991)$ & $1.038(1.021,1.059)$ \\
\hline 1993 & $1.056(1.043,1.079)$ & $1.128(1.103,1.162)$ & $0.960(0.947,0.975)$ & $1.036(1.014,1.055)$ \\
\hline 1994 & $1.092(1.081,1.117)$ & $1.114(1.091,1.146)$ & $1.035(1.026,1.055)$ & $1.059(1.039,1.084)$ \\
\hline 1995 & $1.116(1.103,1.138)$ & $1.149(1.123,1.182)$ & $1.050(1.039,1.067)$ & $1.037(1.015,1.061)$ \\
\hline 1996 & $1.168(1.158,1.199)$ & $1.262(1.247,1.320)$ & $1.045(1.030,1.062)$ & $1.082(1.059,1.112)$ \\
\hline 1997 & $1.170(1.158,1.204)$ & $1.257(1.242,1.314)$ & $1.051(1.033,1.070)$ & $1.031(1.007,1.058)$ \\
\hline 1998 & $1.157(1.139,1.186)$ & $1.236(1.215,1.282)$ & $1.050(1.027,1.068)$ & $1.020(0.995,1.046)$ \\
\hline 1999 & $1.205(1.183,1.235)$ & $1.290(1.261,1.340)$ & $1.089(1.063,1.107)$ & $1.014(0.992,1.045)$ \\
\hline 2000 & $1.298(1.271,1.340)$ & $1.360(1.328,1.434)$ & $1.195(1.162,1.221)$ & $1.029(1.003,1.060)$ \\
\hline 2001 & $1.305(1.275,1.351)$ & $1.353(1.318,1.439)$ & $1.209(1.173,1.236)$ & $1.065(1.035,1.104)$ \\
\hline 2002 & $1.384(1.350,1.436)$ & $1.397(1.351,1.484)$ & $1.295(1.256,1.334)$ & $1.080(1.041,1.125)$ \\
\hline 2003 & $1.401(1.364,1.454)$ & $1.403(1.358,1.484)$ & $1.314(1.273,1.356)$ & $1.054(1.017,1.103)$ \\
\hline 2004 & $1.457(1.423,1.524)$ & $1.512(1.467,1.621)$ & $1.357(1.313,1.403)$ & $1.149(1.102,1.202)$ \\
\hline
\end{tabular}

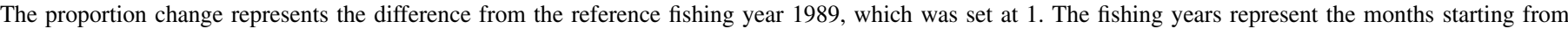
November through to October for eastern king prawns and saucer scallops, and January through to December for tiger, endeavour and red spot king prawns.

average catches across the sectors. Vessels with a turtle excluder device and/or by-catch reduction device tended to have increased catches of endeavour prawns (10\%), red spot king prawns $(7 \%)$, eastern king prawns (13\%) and saucer scallops (5\%), but 3\% smaller catches of northern tiger prawns. Vessels using try nets achieved 5-9\% better catches of tiger prawns.

\subsection{Estimates of fishing power}

Annual increases in average relative fishing power were calculated from the mixed linear model using Eqs. (2) and (3). Changes in fishing power due to vessel upgrades were measured by the fixed effects $\boldsymbol{\beta}_{2}$. Changes due to evolution of each trawl sector's vessel profile were measured through the random vessel terms $(\boldsymbol{\gamma})$, and are illustrated on Fig. 2 by the difference between the overall fishing power estimate (solid line) and the fishing power estimate from the $\boldsymbol{\beta}_{2}$ fixed effects only (dotted line).

Overall the analyses showed consistent annual increases in fishing power. The prawn sectors were influenced mostly by the changing fleet profile and their vessel power (engine rated power and propeller nozzles) and technology (sonar, global positioning systems and computer mapping) factors. For the saucer scallop sector, net configurations were more important than technology factors. Annual rates of fishing power change are presented in Table 2 .

Tiger prawn fishing power in northern waters increased by $8 \%$ between 1989 and 2003. The increases were driven by higher 

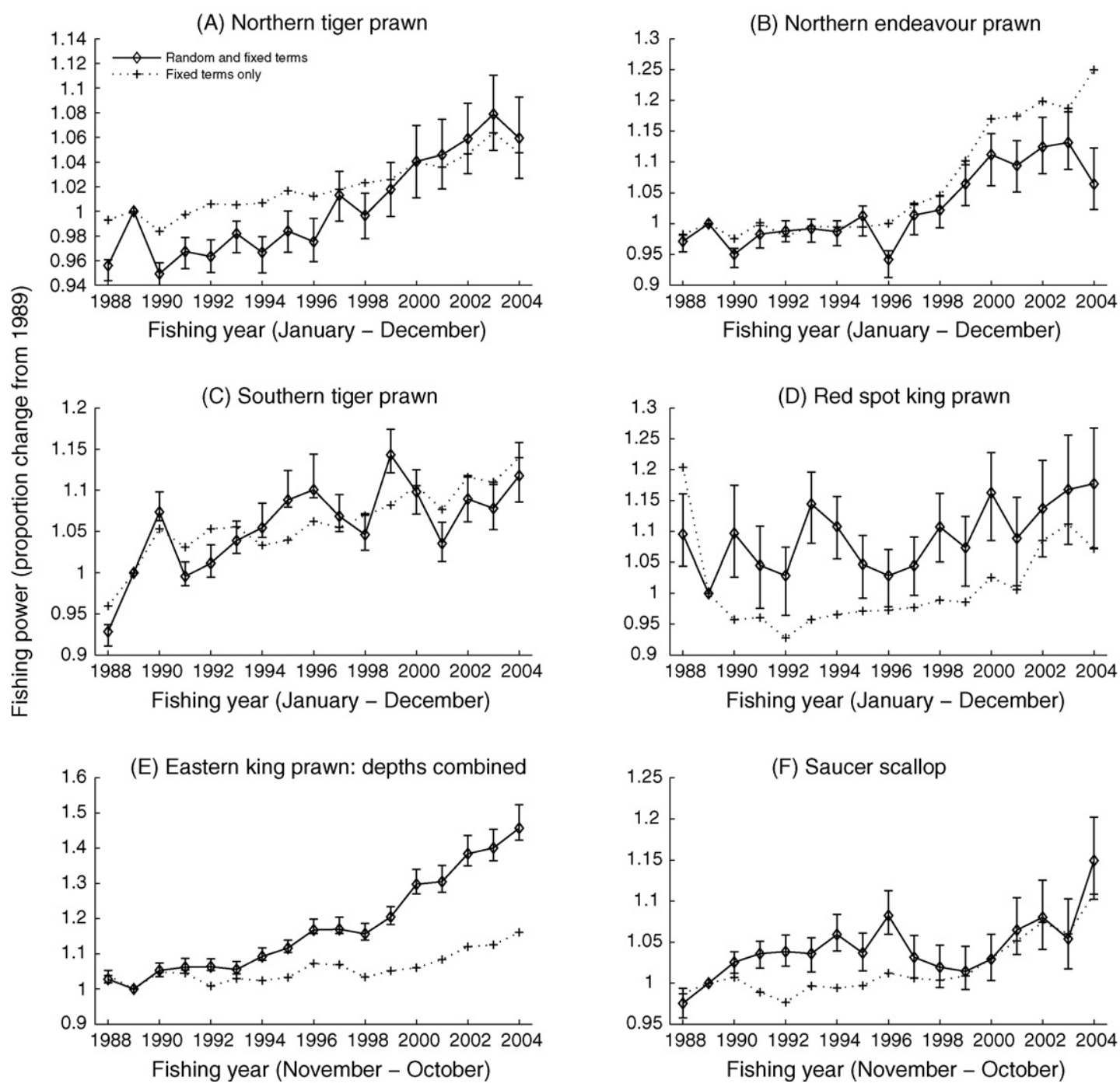

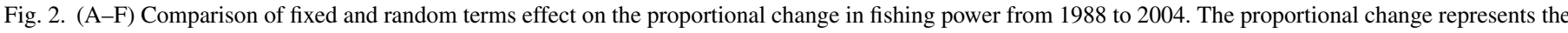
difference from the reference year 1989, which was set at 1. Error bars illustrate the $95 \%$ confidence intervals.

engine power, propeller nozzles, quad net gear, Bison or Louvre/Kilfoil otter-boards, sonar and global positioning systems, together with a trend towards more efficient vessels (i.e. those with high $\boldsymbol{\gamma}$-terms). The latter effect is illustrated by the overall fishing power (fixed + random effects; solid line) converging and then overtaking the fishing power corresponding to vessel upgrades ( $\boldsymbol{\beta}_{2}$ fixed effects; dotted line). The data for 2004 suggested that fishing power had decreased about $2 \%$ due to lower average engine power and less use quad gear. The noticeable 1989 spike in fishing power was due to greater than average effort by efficient vessels.

The increase in northern endeavour prawn fishing power was calculated at 13\% between 1989 and 2003. Most of this fishing power increase occurred between 1996 and 2000. Over these 5 years fishing power increased by $17 \%$. The fishing power increases were mostly driven by higher engine rated power, Bison otter-boards and computer mapping systems. The noticeable drops in the 1996 and 2004 fishing power were due to the more efficient vessels fishing fewer nights.
The results show a trend towards less efficient vessels (lower $\boldsymbol{\gamma}$-terms) in the northern endeavour prawn sector (Fig. 2B, fall in solid line relative to dotted line), as compared to a trend towards more efficient vessels in the northern tiger prawn sector (Fig. 2A). These sectors are fished by similar vessels in similar waters, but tiger prawns are much more valuable. The analyses indicate that efficient fishing vessels may target tiger prawns in preference to endeavour prawns.

Tiger prawn fishing power in southern waters increased by $12 \%$ between 1989 and 2004. Increases in fishing power were associated with improvements in vessels' engine power, and increased use of quad and try trawl nets. Overall there was no trend towards more or less efficient vessels, but random vessel effects $(\boldsymbol{\gamma}$-terms) did contribute extra year to year variation in fishing power.

The analysis estimated increases in fishing power at $18 \%$ between 1989 and 2004, mainly associated with two major effects within definite time periods: arrival of more efficient boats in this sector in 1990, and a substantial increase in average engine power from 2001 to 2003. 
The eastern king prawn sector experienced the largest increase in fishing power. The analysis estimated increases in average annual fishing power of $51 \%$ in shallow waters, $36 \%$ in deep waters and 46\% across all waters between 1989 and 2004. Most of the fishing power increases were measured through the random vessel effects $(\boldsymbol{\gamma})$, which absorbed the parameters for engine rated power, trawl speed and propeller nozzle (Table 1). The results illustrate a large effect of change in fleet composition, whereby less efficient vessels have left the trawl sector, while more efficient ones remained. Also, the vessels that fished both northern tiger and eastern king prawns had expended about $15 \%$ more effort towards eastern king prawns since 2000. The use of computer mapping, sonar, quad trawl gear and by-catch reduction and turtle excluder devices were also important variables contributing to increased fishing power.

Increases in saucer scallop fishing power were $15 \%$ between 1989 and 2004. The random vessel term $(\boldsymbol{\gamma})$ absorbed the fishing power effects of propeller nozzle, sonar and computer mapping, but engine rated power $\left({ }^{* * *} P<0.001\right)$ and quad trawl gear $\left.{ }^{* * *} P<0.001\right)$ were still significant in determining fishing power increases (Table 1). The analysis also indicated that more nights of fishing were expended by the efficient vessels during the high catch years 1990-1996. Catch rates declined after 1996 and the fleet profile changed to less efficient vessels. Since 2000 fishing power increases have been driven by higher engine power and use of quad and try nets.

\section{Discussion}

Fishing power in the Queensland ECOTF increased substantially between 1988 and 2004. Overall the analyses show that annual changes in prawn trawl fishing power were influenced mostly by changing fleet profiles (vessels changing the number of days they fish in each trawl sector, moving between sectors or in some cases exiting the fishery altogether), upgrades to vessel power (engine power and propeller nozzles) and adoption of new technology (sonar, global positioning systems and computer mapping). Net configurations were more important than technology factors in determining saucer scallop fishing power. The results demonstrate the importance of standardising average catch rates according to changes in average annual fishing power. For example, if 1989 catch rates were standardised to 2004 fishing power they would be between 6 and $51 \%$ higher compared to the observed nominal catch rates in 1989 (Table 2). This effect is crucial for stock assessments using catch rates. It is important to note that fishing power estimates do not increase continuously but vary between years. Their influence on estimates of limit reference points such as fishing effort at maximum sustainable yield ( $\left.E_{\mathrm{MSY}}\right)$ needs to be recognised, especially in the selection of the past unit of fishing effort to use as the reference for effort creep in future stock assessments.

Our results confirm that major changes have taken place in vessel characteristics, fishing gear, navigation and communication over the last 17 years. The adoption of global positioning systems, computer mapping software and turtle excluder and by-catch reduction devices are nearing $100 \%$. However, several technologies (e.g. new propeller designs) are yet to be adopted universally by the trawl fleet. Further upgrades in some fleet characteristics, such as engine power and use of trawl quad-nets, can be achieved and are likely to contribute to further increases in fishing power. We also expect new technologies to emerge and be adopted in the future. In addition, each trawl sector's fleet composition will change, affecting its fishing power. Many vessels are currently exiting the fishery in the face of high fuel costs and competition from imported seafood; we expect these vessels to be both less efficient and less powerful than those that remain, contributing to an increase in the fleet's average fishing power.

Global positioning systems, although positively affecting catches in three out of the six sectors, had non-significant $(P>0.05)$ or slight negative effects in the red spot king prawn, eastern king prawn and scallop sectors. This may be due to specific features of these species and their fisheries. Red spot king prawns occur near reefs, allowing visual identification of target areas. Eastern king prawns are much more migratory than tiger/endeavour prawns, occur at much greater depths and are generally fished along narrow depth contours (as illustrated in Queensland waters in Fig. 1C). Skill to find patches of saucer scallop probably does not depend much on use of GPS.

Try gear had a positive effect on tiger and endeavour prawn catches, where its use is widespread (90-100\%). However, red spot and eastern king prawn catches were negatively associated with try gear. Usage of try gear is variable and inconsistent for these species, and less common in deep water where eastern king prawns are found. Our finding of positive effects of BRDs and TEDs on catches of target species in four of the six sectors agrees with other studies (Rogers et al., 1997; Broadhurst and Kennelly, 1997; Steele et al., 2002; Courtney and Campbell, 2003). The negative relationship between trawl speed and catch in the red spot king prawn and saucer scallop sectors may show the importance of trawling at a speed that allows the fishing gear to function as designed.

Fishing power analyses can be affected by 'confounding', whereby it is impossible to determine whether a change in catch rate is due to variation in population abundance or changing fishing power. Confounding is a failing not of the analysis technique but of contrast in the data. It can happen, for example, if all vessels in a fleet undergo identical upgrades at the same time. Confounding is a major problem in Australia's Northern Prawn Fishery (NPF), where there are long seasonal closures and vessel ownership is concentrated in large corporations with similar economic motivation (Dichmont et al., 2003).

Confounding is less evident in our study of the Queensland ECOTF, which has comprised 400-900 active vessels, with about as many owners and a wide range of business strategies. Fleet upgrades usually take place over periods of many years. Nevertheless, ongoing independent data are desirable to verify abundance indices. Available data from fishery-independent surveys show good agreement with the standardised catch rates produced by this study (O'Neill and Leigh, 2006; O'Neill and Turnbull, 2006).

Linear mixed models may also find beneficial applications to other fisheries with large data sets that have evolved from many fishing operations or vessels. In our analysis they have been 
especially useful in resolving changes in fleet profile that go beyond physical characteristics of the vessels. Broader aspects of their use include testing hypotheses of environment effects such as river flows or rainfall on catches (Tanimoto et al., 2006).

\section{Acknowledgements}

The Department of Primary Industries and Fisheries (DPI\&F) funded the project, and we gratefully acknowledge their support. The work would not have been possible without the efforts of many people. Special thanks go to: (1) the trawler owners and skippers who provided technical details on their vessels, their fishing gears and technologies, (2) Dr. Anthony Courtney, Mr. Clive Turnbull, Ms. Cassandra Rose, Ms. Joanne Atfield, Mr. Bart Mackenzie, Mr. Chris Barber and Ms. Sarah Kistle who contributed to the survey design, logistics and data collection on vessel fishing gears and technologies and (3) Ms. Kate Yeomans and Mr. Jeff Bibby for providing the prawn and scallop catch data from the DPI\&F commercial fishery compulsory daily logbook database (CFISH). Dr. Rick Officer made constructive comments on earlier versions of this manuscript. This work was reviewed by Dr. Ian Poiner (Australian Institute of Marine Science), Dr. Bill Venables (Commonwealth Scientific and Industrial Research Organisation) and Dr. Nick Rawlinson (Australian Maritime College), who all have researched Australia's Northern Prawn Fishery. We also thank the two anonymous journal reviewers for their valuable comments.

\section{References}

Bishop, J., Die, D., Wang, Y.-G., 2000. A generalized estimating equations approach for analysis of the impact of new technology on a trawl fishery. Aust. N.Z. J. Stat. 42, 159-177.

Bishop, J., Venables, W.N., Wang, Y.-G., 2004. Analysing commercial catch and effort data from a Penaeid trawl fishery. A comparison of linear models, mixed models, and generalised estimating equations approaches. Fish. Res. 70, 179-193.

Broadhurst, M.K., Kennelly, S.J., 1997. The composite square-mesh panel: a modification to codends for reducing unwanted bycatch and increasing catches of prawns throughout the New South Wales oceanic prawn-trawl fishery. Fish. Bull. 95, 653-664.

Courtney, A.J., Cosgrove, M.G., Mayer, D., Vance, D.J., 2002. Developing indicators of recruitment and effective spawner stock levels in eastern king prawns (Penaeus plebejus). Fisheries Research and Development Corpora- tion (FRDC) Final Report, Department of Primary Industries, Queensland, Project \#97/145, Brisbane. http://www2.dpi.qld.gov.au/far/9348.html.

Courtney, A.J., Campbell, M., 2003. DPI studies bycatch in scallop fishery. J. Queensland Seafood Ind. Assoc. Queensland Fisherman 21 (9), 39-43.

Dichmont, C.M., Bishop, J., Venables, B., Sterling, D., Penrose, J., Rawlinson, N., Eyres, S., 2003. A new approach to fishing power analysis and its application in the Northern Prawn Fishery. CSIRO, Report No: R99/1494.

GenStat, 2005. GenStat, eighth ed. Lawes Agricultural Trust.

Hall, N.G., Penn, J.W., 1979. Preliminary assessment of effective effort in a two species trawl fishery for penaeid prawns in Shark Bay, Western Australia. In: Population assessment of shellfish stocks, Rappo. P.-V. Reun. CIEM. pp 147-154.

Kerrigan, B., Gaddes, S., Norris, W. (eds.), 2004. Review of the sustainability of fishing effort in the Queensland East Coast Trawl Fishery, The State of Queensland, Department of Primary Industries and Fisheries, Report QI04067. http://www2.dpi.qld.gov.au/far/17788.html.

Montgomery, D.C., 1997. Design and Analysis of Experiments, fourth ed. John Wiley and Sons, New York.

O’Neill, M.F., Courtney, A.J., Good, N.M., Turnbull, C.T., Yeomans, K.M., Staunton Smith, J., Shootingstar, C., 2005. Reference Point Management and the Role of Catch-Per-Unit Effort in Prawn and Scallop Fisheries. Department of Primary Industries and Fisheries, Queensland, FRDC Project 1999/120 http://www2.dpi.qld.gov.au/far/17791.html.

O'Neill, M.F., Courtney, A.J., Turnbull, C.T., Good, N.M., Yeomans, K.M., Staunton-Smith, J.S., Shootingstar, C., 2003. Comparison of relative fishing power between different sectors of the Queensland trawl fishery, Australia. Fish. Res. 65, 309-321.

O’Neill, M.F., Leigh, G.M., 2006. Fishing Power and Catch Rates in the Queensland East Coast Trawl Fishery. Department of Primary Industries and Fisheries, Queensland, QI06051 http://www2.dpi.qld.gov.au/far/18577.html.

O'Neill, M.F., Turnbull, C.T., 2006. Stock Assessment of the Torres Strait Tiger Prawn Fishery (Penaeus esculentus). Department of Primary Industries and Fisheries, Queensland, QI05132 http://www2.dpi.qld.gov.au/ far/18576.html.

Robins, C.J., Wang, Y.-G., Die, D., 1998. The impact of global positioning systems and plotters on fishing power in the northern prawn fishery, Australia. Can. J. Fish. Aquat. Sci. 55, 1645-1651.

Rogers, D., Rogers, B., de Silva, J., Wright, V., 1997. Effectiveness of four industry-developed bycatch reduction devices in Louisiana's inshore waters. Fish. Bull. 95, 552-565.

Salthaug, A., Godø, O.R., 2001. Standardisation of commercial CPUE. Fish. Res. 49, 271-281.

Steele, P., Bert, T.M., Johnston, K.H., Levett, S., 2002. Efficiency of bycatch reduction devices in small otter trawls used in the Florida shrimp fishery. Fish. Bull. 100, 338-350.

Tanimoto, M., Courtney, A.J., O’Neill, M.F., Leigh, G.M., 2006. Stock assessment of the Queensland (Australia) east coast banana prawn (Penaeus merguiensis) fishery. Department of Primary Industries and Fisheries, Queensland, QI06067 http://www2.dpi.qld.gov.au/far/18571.html. 